\title{
Towards a sustainable material use in the automotive industry: Life Cycle Costing and socio-technical approach to material use
}

\author{
Nabila Iken ${ }^{1, *}$, Stéphane Morel $^{2}$, and Franck Aggeri ${ }^{1}$ \\ ${ }^{1}$ CGS Mines ParisTech, Paris, France \\ 2 Techocentre Renault, Guyancourt, France
}

Received: 20 August 2019 / Accepted: 13 December 2019

\begin{abstract}
The purpose of the article is twofold. We first present a Life Cycle Costing methodology applied at different scales to compare between design options in terms of materials use: in an automobile vehicle part, a whole vehicle, and a car manufacturer's portfolio. The Life Cycle Costs consider costs for different stakeholders, including environmental damage costs (supported by the civil society), fuel expenses (supported by the customer) and materials costs (supported by the car manufacturer). The second objective of the article is to bring a management and socio-technical vision to the issue of material use in the automobile industry, in order to challenge the idea that all decisions regarding material use depend on purely technical and economic criteria. Through a qualitative research, we investigated the barriers to material efficiency and integrating the environmental criterion in decision making from a French car manufacturer's perspective. Within the same company, we also collected material experts' feedbacks on the LCC tool developed in the first Part, both in terms of methodology and potential integration in decision-making.
\end{abstract}

Keywords: Life Cycle Costing / materials use / automobile industry / socio-technical approach

Résumé. Vers un usage durable des matériaux dans l'industrie automobile : Coût du Cycle de Vie et approche socio-technique de l'usage des matériaux. Le but de cet article est double. Nous présentons d'abord une méthodologie de calcul du Coût du Cycle de Vie appliquée à différentes échelles pour comparer les options de conception en termes d'utilisation de matériaux: dans une pièce de véhicule automobile, un véhicule entier et le portefeuille d'un constructeur automobile. Les Coûts du Cycle de Vie tiennent compte des coûts pour les différentes parties prenantes, y compris les coûts des dommages environnementaux (pris en charge par la société civile), les frais de carburant (pris en charge par le client) et les coûts des matériaux (pris en charge par le constructeur automobile). Le deuxième objectif de l'article est d'apporter une vision managériale et sociotechnique à la question de l'usage des matériaux dans l'industrie automobile, afin de remettre en cause l'idée que toute décision concernant l'utilisation des matériaux dépend de critères purement techniques et économiques. Dans le cadre d'une recherche qualitative, nous avons étudié les obstacles à l'efficacité matière et l'intégration du critère environnemental dans la prise de décision du point de vue d'un constructeur automobile français. Au sein de la même entreprise, nous avons également recueilli les retours d'experts sur l'outil CCV développé dans la première partie, tant en termes de méthodologie que d'intégration potentielle dans la prise de décision.

Mots clés: coût du cycle de vie / usage des matériaux / industrie automobile / approche sociotechnique

\section{Redefining the value of materials through a holistic indicator}

\subsection{Introduction: why a Life Cycle Cost?}

In the corporate world and beyond, our vision of the world is shaped by a multitude of indicators and representations: growth rate, operating margin, all kinds of KPIs, etc. These

\footnotetext{
* e-mail: nabila.iken@mines-paristech.fr
}

allow us to reduce the complexity of the phenomena that interest us, in order to act and make decisions for a specific purpose [1]. However, these representations are not neutral: they put some aspects in visibility while putting others in "invisibility" [2]. Thus, the usual performance indicators on which decision-makers base their design choices in businesses, in particular economic indicators such as production costs or market prices, offer a limited view both in width (only part of the life cycle of products and services) and in depth (only one stakeholder). Indeed, 
Table 1. Costs considered in the LCC assessment.

\begin{tabular}{llll}
\hline Life Cycle Stage & Raw materials extraction & Use & End of life \\
\hline Direct costs & Purchase at market price & Fuel consumption & $/$ \\
Supported by & Car manufacturer & Customer & $/$ \\
External costs & Cost of pollution and energy & $\begin{array}{l}\text { Production and combustion } \\
\text { of fuel }\end{array}$ & End-of-life pollution credit \\
Supported by & Society & & \\
\hline
\end{tabular}

these indicators do not highlight pollution transfers to upstream phases of products life cycles, but also costs transfer to other stakeholders, the civil society in particular.

Moreover, today's regulatory context in Europe tends to encourage car constructors to electrify their fleet, by imposing increasingly strict $\mathrm{CO}_{2}$ emission limits during the use phase [3]. The optimization of emissions in this life cycle phase will probably lead to a pollution transfer in the upstream phases of vehicles life cycle, which will make materials play a more important role in the overall environmental impact of vehicles and draw the attention of regulators to this phase. This demonstrates the need of car manufacturers to develop a relevant tool to manage this change of focus.

To address this issue, we explore more holistic indicators such as Life Cycle Costing, with the aim of highlighting hidden costs (or externalities) of certain materials in the automotive industry. Our underlying assumption is that environmental externalities are a measure of risks and opportunities for businesses, and a way to capture signals that would otherwise be invisible. To investigate the potential of such a tool, we apply this LCC methodology at several levels: at the scales of an automobile part, a whole vehicle, and an automobile manufacturer (based on a representative selection of vehicles). The aim is to estimate the materials cost throughout the life cycle of vehicles for several stakeholders: the automobile manufacturer, the customer, and the civil society. This allows in addition to clarify the distribution of costs among these stakeholders over the entire life cycle.

\subsection{Method}

\subsubsection{Life Cycle Costing principle}

Life Cycle Costing (LCC) is an economic tool that evaluates the costs of a product or a system (usually a project or a process) throughout its life cycle, over a defined time horizon. It is possible to include in the LCC assessment direct costs only (Scope 1 in the Fig. 1) but it is also possible to expand the scope to include the costs of different environmental externalities (Scope 2 in Fig. 1), such as the costs of greenhouse gases emissions or resource depletion [4]. In order to include these costs, a parallel Life Cycle Assessment (LCA) is required to determine emissions and resource consumption due to the studied project or process [5]. Furthermore, other kinds of externalities like social externalities may be considered

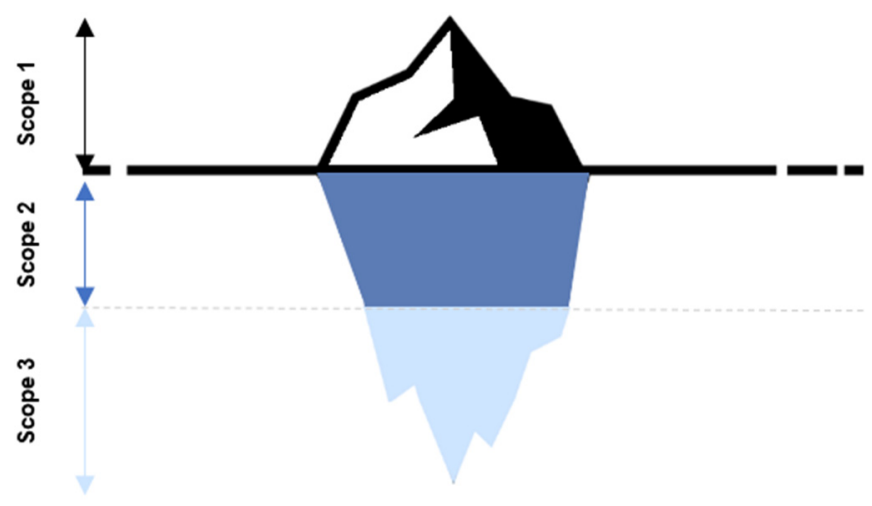

Fig. 1. Life cycle costing perimeter.

(Scope 3 in the Fig. 1), such as bad working conditions or cultural heritage destruction [6]. In our study we considered only environmental externalities (Scope 2).

\subsubsection{Calculation assumptions}

The costs considered in our LCC methodology applied to different materials at each stage of the life cycle and for the three stakeholders considered are summarized in the Table 1.

Logistics impacts are not considered for the assessment at the level of a vehicle part (Sect. 1.3.1). For assessments at the level of a whole vehicle (Sects. 1.3.2 and 1.3.3), the logistics is modelled in two phases: the inbound logistics phase (it considers the transport of parts such as gear boxes, engines, body parts, etc. inside plants, and a corporate average value of logistics between plants), and the outbound logistics phase (from plants to car dealerships).

\subsubsection{The car manufacturer}

Internal costs for the car manufacturer are assimilated to the purchase price of raw materials, based on the average market price over the year 2018 when possible, otherwise they were based on experts' recommendations. Indeed, logistics and processing costs are not considered in the calculation, because the available data at this stage of the study did not allow these parameters to be included. The validity of this assumption depends very much on the parts considered, as the cost of raw materials may be the largest cost item for some parts (for example catalytic converter) but not in every case. Hence a next step for our study would be to consider costs distribution in more details. 
Table 2. Holdbrook's typology of value in the customer experience.

\begin{tabular}{llll}
\hline & & Extrinsinc & Intrinsic \\
\hline \multirow{2}{*}{ Self-oriented } & Active & Efficiency $\left(\mathrm{O} / \mathrm{I}^{\mathrm{a}}\right.$, convenience) & Play (fun) \\
& Reactive & Excellence (quality) & Aesthetics (beauty) \\
Other-oriented & Active & Status (success, impression, management) & Ethics (justice, virtue, morality) \\
& Reactive & Esteem (reputation, materialism, possessions) & Spirituality (faith, ecstasy, sacredness) \\
\hline
\end{tabular}

a Output/input ratio.

\subsubsection{Society}

The calculation of the external costs (environmental damage costs) supported by civil society is based on the EPS2015d $\mathrm{d}^{1}$ impact assessment method, which is implemented in the GaBi LCA software. The EPS system was developed by the IVL Swedish Environmental Research Institute, Volvo and the Swedish Federation of Industries ${ }^{2}$ in order to help designers choose among design options in product and process development [7].

The EPS system considers impacts from emissions and resources consumption that cause significant changes in any of the 5 following safeguard subjects: eco-system services, access to water, abiotic resources, human health and biodiversity. It allows to estimate the damage costs for emissions and use of resources based on LCA results, using different economic valuation methods to determine the willingness to pay (WTP) associated with each damage. For instance, contingent valuation is used to evaluate the WTP for human health, abatement costs for abiotic resources, market price for ecosystem, etc. Moreover, global average damage costs for emissions and resources are estimated by using the values of an average OECDinhabitant. The results of the EPS impact assessment method are damage costs for emissions and use of natural resources expressed in monetary unit (Euro of environmental damage). In our calculation, we considered only environmental costs for emissions and excluded environmental costs for resources. This methodological choice is on the one hand due to the fact that the resource issue is managed in the company through other tools, and on the other hand, because we consider that the material cost partly reflects the scarcity of materials and their energy intensity. Indeed, this work has been conducted within the Material Engineering Department of a car manufacturer, with the aim of enriching the existing environmental management tools that already cover the resource aspects (material criticality, recycling, fossil fuel dependency, etc.). Thus, the EPS assessment focused on emissions damages brings a new information in decision-making.

\subsubsection{The customer}

What is the value and what is the cost that customers attribute to materials? How can it be measured? The

\footnotetext{
${ }^{1}$ Environmental Priority Strategy.

2 https://www.ivl.se/english/startpage/pages/our-focus-areas/ environmental-engineering-and-sustainable-production/lca/eps. html.
}

answer to these questions is not obvious, and seems not to have been researched until now, let alone in the automotive sector and with a quantitative approach $[8,9]$. Indeed, customer value concept entails several dimensions, from the most material to the most spiritual, some of which depend very much on individual values, as shown by the Table 2 [10]:

In our LCC assessment, we considered the dimension of customer value that can be directly objectified with the available data, which is the efficiency dimension. Indeed, we have assimilated the costs related to materials for the customer to the cost of fuel consumption related to mass. Knowing that the latter depends on several factors (aerodynamics of the vehicle, electronic equipment consumption, rotational inertia, etc.), we considered that one third of the total fuel consumption is related to mass [11]. That means that for a vehicle that consumes $6000 \mathrm{~L}$ during its lifespan, a third of this consumption $(2000 \mathrm{~L})$ is due to mass, which induces a cost of $2800 €$ (with a fuel price of $1.4 € / \mathrm{L}$ ). Therefore, for the calculation at the level of a vehicle part (Sect. 1.3.1), we used mass to allocate the environmental costs and fuel consumption to the parts studied.

\subsection{Results}

1.3.1 Life cycle cost at the level of a part: case of a clutch pedal

As mentioned in Section 1.2.1, the assessment of costs during the use phase (which are the costs for the customer) at part level depends on the vehicle considered and its fuel consumption. In this calculation, we considered an SUV vehicle of $1380 \mathrm{~kg}$ with gasoline engine, a lifespan of 10 years $(150000 \mathrm{~km}$ covered), and a fuel consumption of $5.9 \mathrm{~L} / 100 \mathrm{~km}$. The aim of the assessment is to compare different materials options for the polymer part of a clutch pedal, that can be made of different types of polymers (primary polypropylene, recycled polypropylene or polyamide6). Figure 2 illustrates the Life Cycle Costing results.

The results show that the use of polyamide6, rather than primary or recycled polypropylene, is more costly both for the car manufacturer and civil society. In this particular case, taking into account environmental externalities and costs to the customer does not change the conclusion about the performance of these materials, compared to simple economic analysis based on direct costs. Nevertheless, these results widen the gap between these different materials and can be used as an additional argument to promote for example recycled polypropylene and help accelerate its deployment. 
LCC of a clutch pedal with different polymers $(€)$

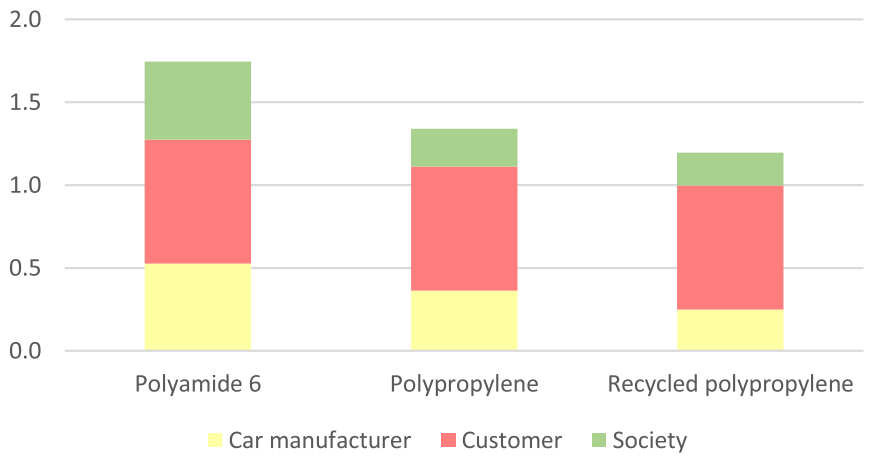

Fig. 2. LCC of a clutch pedal with polypropylene, recycled polypropylene and polyamide6 - whole life cycle.
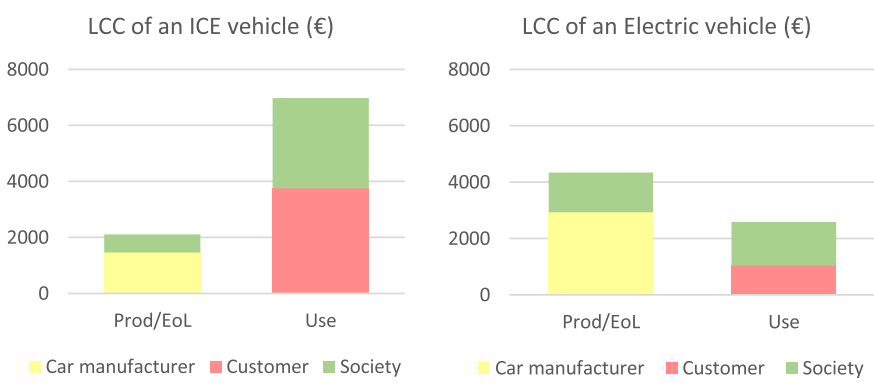

Fig. 3. LCC of an ICE vehicle and an electric vehicle-Production and use.
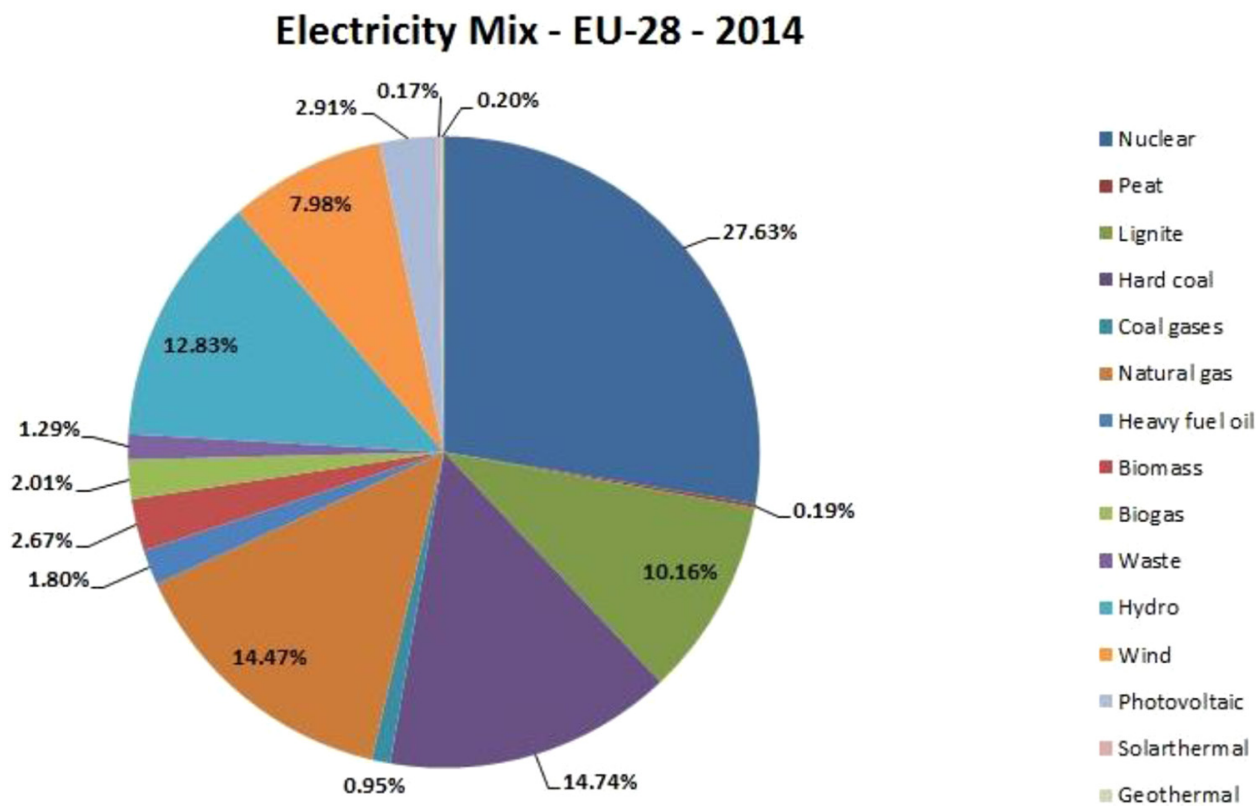

Fig. 4. 2014 European average electricity mix used in the assessment.

\subsubsection{Life cycle cost at the level of a vehicle: ICE versus electric vehicle}

To demonstrate the value of applying the LCC approach to vehicles, we applied the methodology described in Section 1.2 to a gasoline internal combustion engine vehicle of $1015 \mathrm{~kg}$ and an electric vehicle of $1463 \mathrm{~kg}$ with a $22 \mathrm{~kW}$ battery, based on the materials they contain. Figure 3 shows that the use phase has more impact than the production phase both for the electric vehicle and the ICE vehicle. In the calculations of the use phase for the electric vehicle, we used a European average electric mix based on the 2014 energy mix with $42 \%$ fossil, $28 \%$ of nuclear and $30 \%$ renewable energy, as illustrated in Figure 4. This results in a carbon footprint of $450 \mathrm{~g} / \mathrm{kWh}$. Figure 5 illustrates the LCC of the two vehicles throughout their whole life cycle.
The results for electric vehicles are closely linked to electricity mix. Indeed, considering a French electricity mix would have reduced the environmental cost of the electric vehicle use phase of more than $85 \%$, because of the large share of nuclear energy in the French electricity mix $(78 \%)$.

However, it is important to keep in mind the methodological choices made especially regarding the environmental costs of resource consumption. Indeed, only environmental costs of emissions are considered here which may bias the interpretation of the results. In fact, considering only emissions doesn't highlight, on the one hand, the additional consumption of material resources due to the production of the battery, and on the other hand, the fact that electric vehicles partly consume renewable energy rather than fossil energy (in this European context). Moreover, these results show the additional investment 
LCC of a vehicle $(€)$

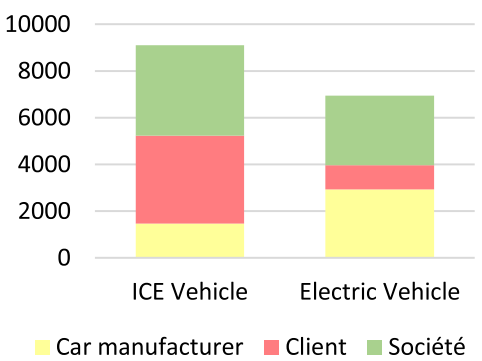

Fig. 5. LCC of an ICE vehicle and an electric vehicle-Whole life cycle.

required from the car manufacturer for electric vehicles, which is due to the production of battery. Regarding the customer, the fuel expenses are lesser in the case of electric vehicles compared to ICE vehicles, due to the price of fuel.

Furthermore, assessing for environmental externalities and costs for the customer illustrates the benefits induced by electric vehicles both for civil society and customers, which may serve as a support for dialogue with stakeholders, whether governments or local collectivities, decision-makers within the company or customers. This has for example been experimented by Volvo Bus to promote electric buses to local authorities in Sweden [12].

\subsubsection{Life cycle cost at the level of the company's portfolio}

By applying the same methodology to a representative set of products and considering their different selling volumes over a year, it becomes possible to compare all the vehicles in the car manufacturer's portfolio in terms of direct costs (materials costs for the car manufacturer) and external costs (environmental damage costs for the society) as illustrated by the Figure 6 , where the size of the bubbles represents the sale volumes. It is also possible to look at the cost distribution between different stakeholders (in this case the car manufacturer, the customer and civil society), due to the production and use of all the vehicles produced by the company over a year (Fig. 7).

This Portfolio Analysis illustrates the positioning of each vehicle in terms of costs for the car manufacturer, costs for civil society and sales volume. Vehicle differentiators are their size and mass, but also their material content, type of engine, and fuel consumption also influence the results. This may serve as a management tool for the car manufacturer to build a portfolio that minimizes its costs and the costs for society. Indeed, this mapping allows to identify the costliest vehicles for civil society, which are the riskiest for the company in the long term (for example Vehicle 6), but also the vehicles that create more value for society and requires more investments today (for example Vehicle 1). This management tool may serve as a basis to build a corporate product strategy. This is for example central to Solvay's sustainability strategy [13].
In the figure above, the cost is proportional to the surface of each rectangle. This illustrates the proportion of costs of environmental externalities borne by society (green part), in particular during the use phase of vehicles. The red part represents the costs on all the life cycle due to fuel consumption, which are borne by the customers. This tool provides a macroscopic view of the company's activity during a year and can be used for example to follow the evolution of costs distribution between the different stakeholders considered from one year to another.

\subsection{Discussion}

\subsubsection{The exhaustivity of the assessment}

In the frame of this study, we developed a Life Cycle Costing method applied to materials, including the purchase cost supported by the car manufacturer, the cost of environmental damages (due to the production and the use of materials) supported by society, and the cost of materials for the customer. Indeed, we used several simplifying assumptions that are more or less strong depending on the case.

For instance, the assimilation of the costs of materials to the purchase price of materials can be aberrant if we study parts whose cost of processing is higher than the cost of raw materials. This is the case of electronic parts. The cost of production scrap is also not taken into account. In addition to manufacturing costs, many costs have not been considered. For example, maintenance cost for the customer, or the cost of socio-economical externalities for society (for instance, materials that are more likely to vibrate induce more noise and therefore more cost to society), and direct costs for the company related to European regulations, such as the $\mathrm{CAFE}^{3}$. Our methodological choice is justified by the fact that CAFE regulation is managed by other entities in the company. However, allocating a CAFE-cost to each material in each part and integrating them in the LCC assessment would give another perspective, as it would strongly favor materials that reduce emissions during the use phase.

Furthermore, considering only environmental damage costs for emissions and eliminating those related to the consumption of resources was a bias that resulted from a compromise between the search for completeness of the method and relevance for the company vis-à-vis its current concerns. One possible way of improving the methodology would be for example to weight material costs with a supply risk factor that considers among others material scarcity, geopolitical, social and regulatory contexts in which materials are produced.

\footnotetext{
${ }^{3}$ Corporate Average Fuel Economy. From 2021, phased in from 2020, the EU fleet-wide average emission target for new cars will be $95 \mathrm{~g} \mathrm{CO}_{2} / \mathrm{km}$. If the average $\mathrm{CO}_{2}$ emissions of a manufacturer's fleet exceed its target in a given year, the manufacturer must pay an excess emissions premium of $95 €$ for each subsequent $\mathrm{g} / \mathrm{km}$ for each car registered.
} 


\section{Portfolio Analysis}

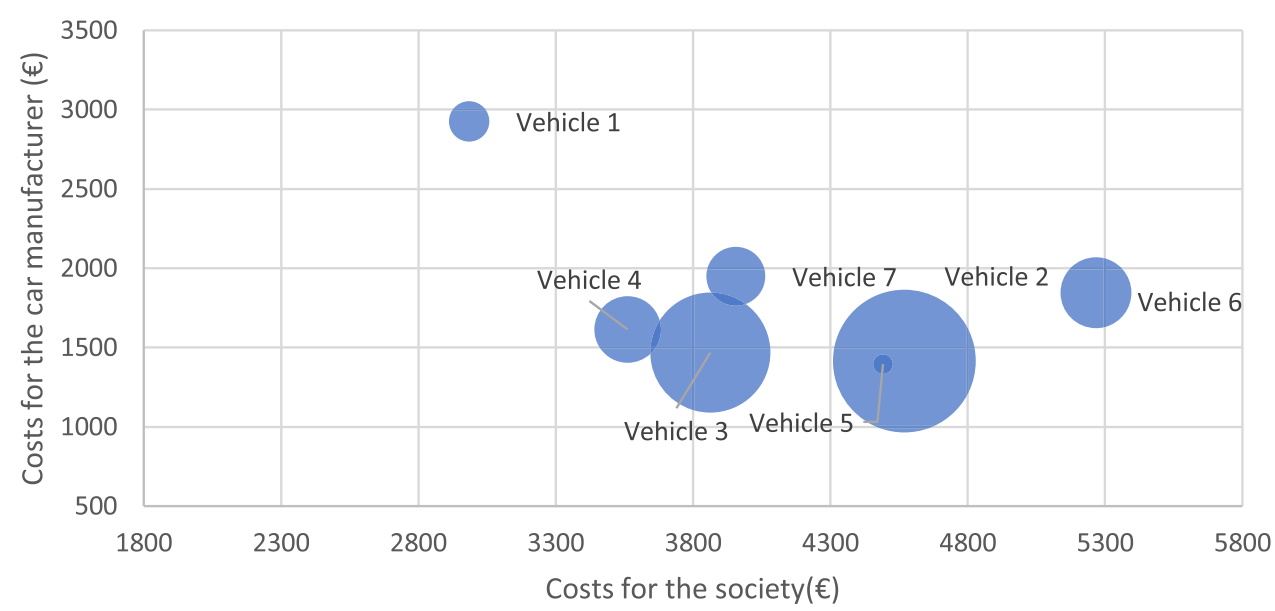

Fig. 6. Costs of the entire portfolio for the car manufacturer and civil society.

Costs distribution due to the production and use of all the vehicles produced during a year $(€)$

Car manufacturer $\square$ Customer $\square$ Society (Production) $\square$ Society (use)

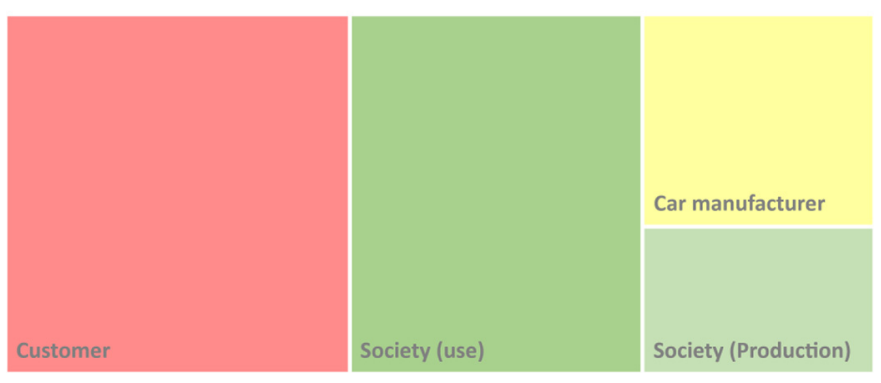

Fig. 7. Costs distribution between the car manufacturer, the customers and civil society due to the production and use of materials in all the vehicles produced during a year.

\subsubsection{The limits of an analysis at the scale of a part}

Some parameters that are empirically measurable at the scale of a vehicle are hard to allocate between different parts. For example, we considered in our assessment that a third of the fuel consumption of a vehicle is due to mass, which can be allocated to each part according to its mass. But the remaining two thirds of fuel consumption are related to other properties such as aerodynamics, electricity consumption, rolling resistance or rotational inertia, which greatly complicates the calculation and increases the amount of data required to perform the evaluation. The problem did not arise for the example of the clutch pedal because we considered that this part only contributes to consumption by its mass (not by its shape, its electricity consumption or its rolling resistance for example).

\subsubsection{Rigor of the economic calculation}

It should also be noted that no discounting rate has been used in our LCC assessments, which is not in line with the
Table 3. Current value of $1000 €$ in 10 years according to the discount rate.

\begin{tabular}{llll}
\hline Discount rate & $4 \%$ & $6 \%$ & $8 \%$ \\
\hline $\begin{array}{l}\text { The current value of 1000€ } \\
\text { spent in 10 years }\end{array}$ & 675.56 & 558.39 & 463.19 \\
\hline
\end{tabular}

financial calculation rules, according to which costs that are not incurred at the same time do not have the same value (see Tab. 3). Indeed, if we can consider that the materials costs for the car manufacturer occur immediately, the fuel expenses of the customer are distributed during all the lifespan of the vehicle, and the cost of the externalities as well.

All things considered, no discount rate is applied in the EPS methodology, because the method aims to value future generations as much as present generations. We have not applied a discounting rate in the calculation of the other costs either, nor an indexation of raw materials or of fuel prices. Nevertheless, as the aim of the assessment is to compare between different design options over a ten years period, this integrating a discounting rate would not change the conclusions.

\section{Socio-technical study and management approach of materials in the automotive industry}

\subsection{Introduction}

According to the IEA, the production and processing of the five most $\mathrm{CO}_{2}$-intensive materials (steel, cement, plastic, paper and aluminum) are at the origin of more than half of the global industrial emissions [14]. Moreover, the automotive industry consumed $9 \%$ and $18 \%$ of global steel and aluminum flows respectively in 2008 [15], as shown by Figure 8 

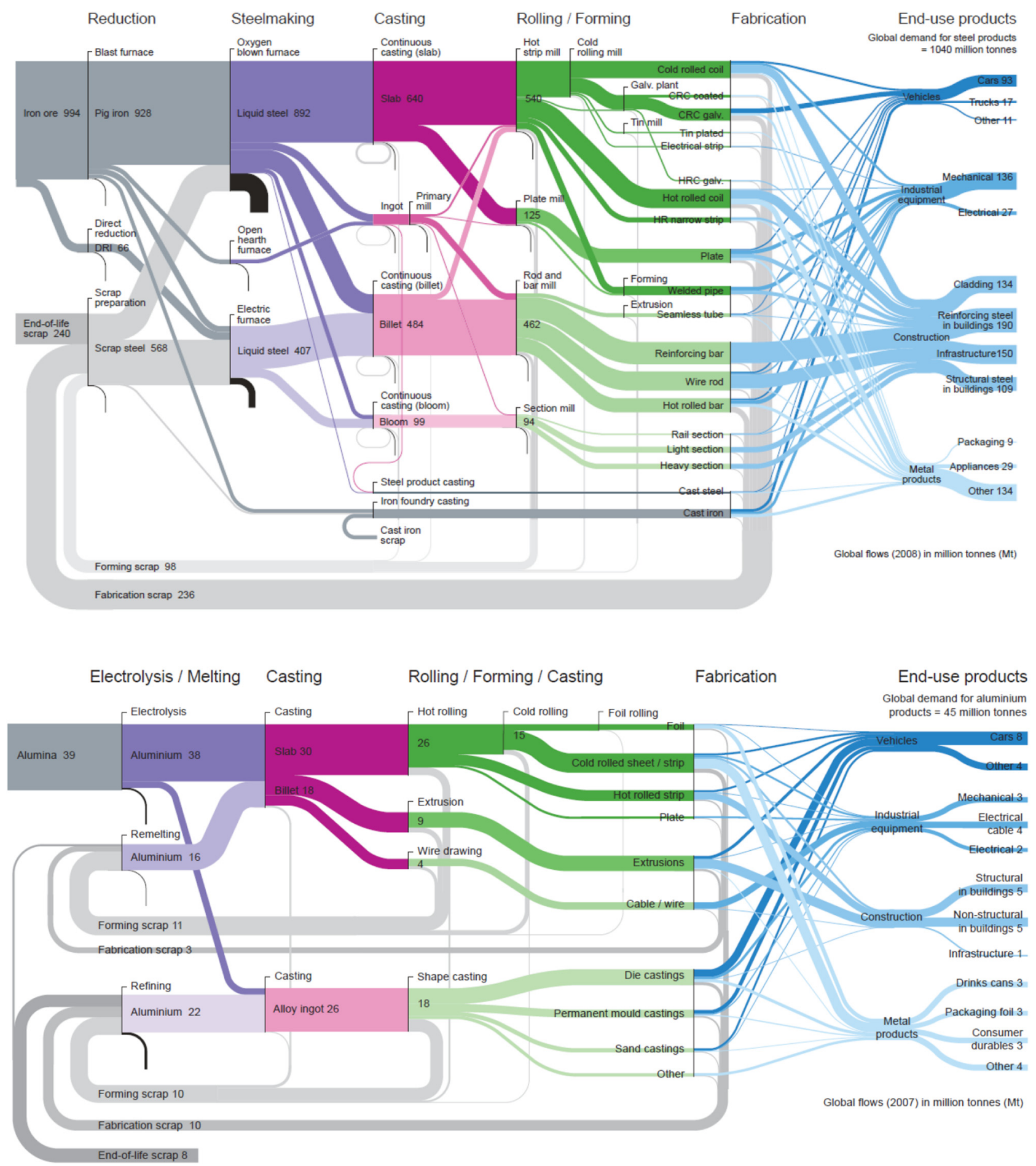

Fig. 8. Global steel and aluminum flows in Mt in 2008. Source: Allwood and Cullen [15].

Therefore, several studies investigated strategies and opportunities for material efficiency improvement in the industrial sector [16,17], whether at the design phase through material substitution, light-weighing, etc., the production phase through yield improvement, materials property improvement, etc. or the use phase with more intensive use, modularity, etc. Figure 9 illustrates some material efficiency improvement strategies at different life cycle stages: design, production and use. Moreover, these strategies are classified according to whether they require a change of design or not, and whether they require more or less material production.

However, car manufacturers face difficulties in implementing sustainable materials management strategies [18], as evidenced by the continuing trend towards an increase in the mass of new passenger cars in Europe, which is partly 


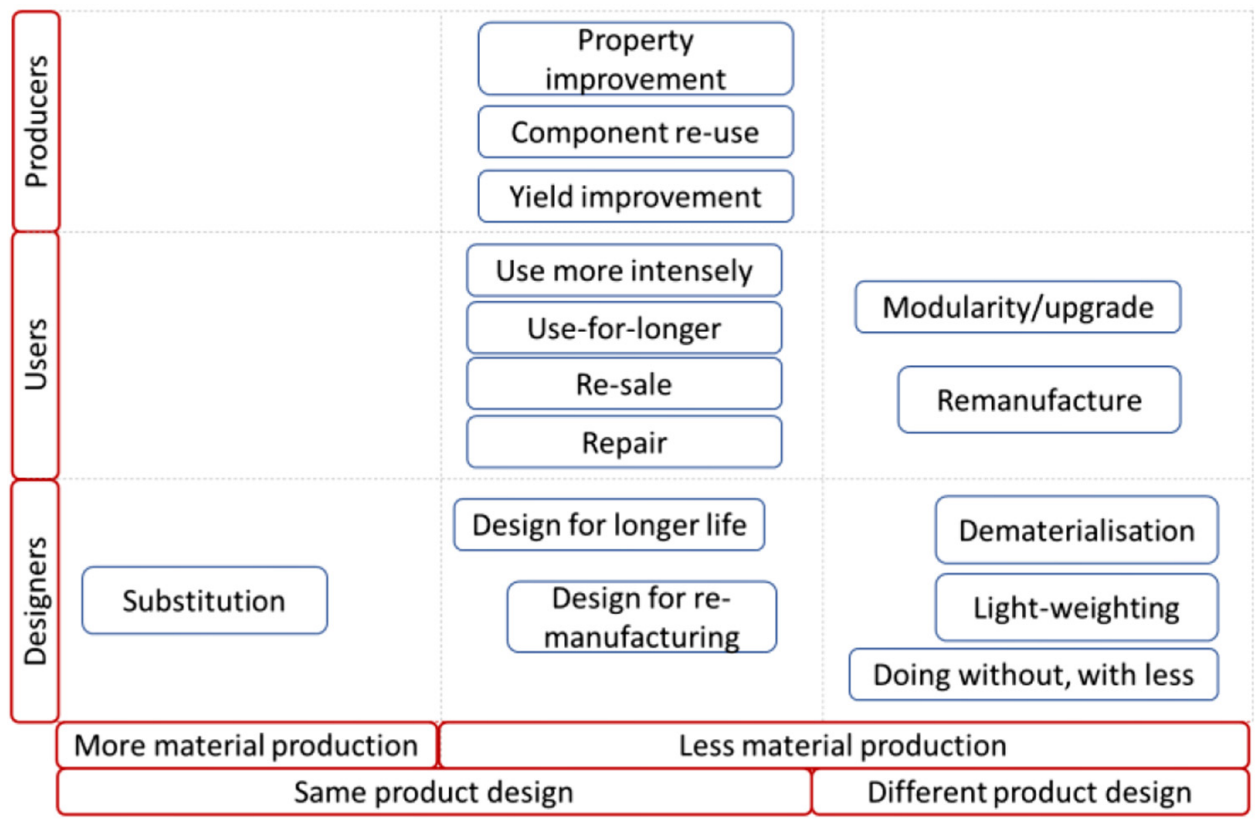

Fig. 9. Material efficiency strategies. Source: adapted from Allwood et al. [16].
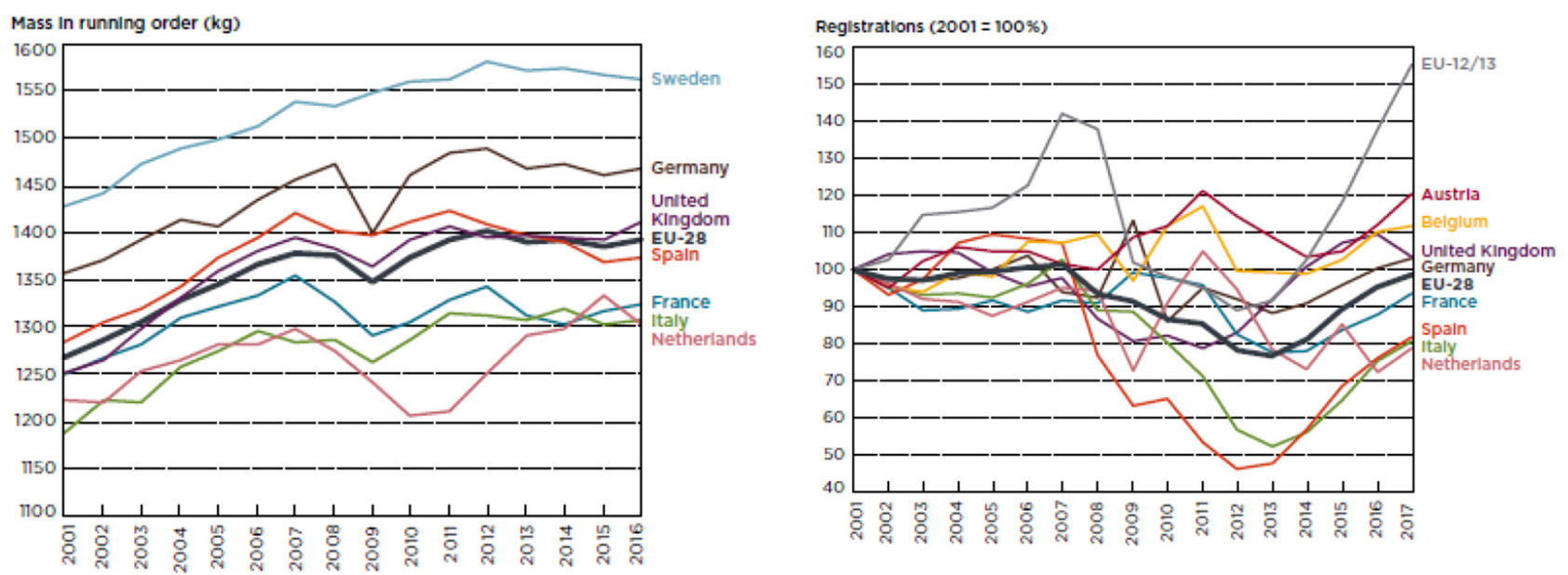

Fig. 10. Evolution of the mass in running order of new passenger cars and evolution of the number of new registration in Europe. Source: ICCT [20].

due to the general increase of vehicle volume but also the use of more and more safety, emission control and luxury equipment [19]. In addition to that, new car registrations in the EU are also tending to increase [20], which highlights a growing material throughput in the automobile industry (Fig. 10).

On the other hand, studies that examined why the adoption of material efficiency strategies is limited have most often adopted a "techno-economic" analytical framework. In this type of studies, companies and decisionmakers are considered as perfectly informed and rational, and decisions regarding material use are mainly determined by cost considerations [21].
An alternative perspective is proposed by "sociotechnical" studies, which consider that decisions made by individuals and companies regarding the use of materials are always influenced by their social, technical, political, cultural and economic context. Decisions are therefore placed within broader complex and multidimensional systems (such as the system of the automobility), which are characterized by a certain stability and favor inertia and reproduction [22]. For example, socio-technical studies have explained how designers and car manufacturers are influenced by the operational context in which they operate, which has important implications for the use of materials in the automotive industry. Nevertheless, little 
research has been conducted on lock-in mechanisms that specifically prevent the adoption of material efficiency strategies by car manufacturers [21]. Our work aims to address this gap in the socio-technical literature by investigating the barriers to material efficiency in the automotive industry and through a qualitative survey in a French car manufacturer.

The first step of our work aims to provide a general overview of the types of obstacles that material experts may encounter in implementing material efficiency solutions and reducing the environmental impact of materials at a French car manufacturer. The second step allowed us to go a little further by analyzing the situation using a tool that served as a probe to highlight the determinants of the decision more specifically. Indeed, according to management scholars, the confrontation between tools and organizations helps reveal their internal operating laws [23].

For this reason, we explored the confrontation between a holistic indicator (the extended Life Cycle Cost of materials, see Part I) and decision-makers (materials experts) to investigate the effect of these kinds of management tools on their decisions and see how they can impulse a better consideration of environmental impact in their material choices. Indeed, we presented the results of applying this methodology to vehicles parts of their respective perimeters. The objective of this process was to collect their feedbacks on the methodology, to identify obstacles and opportunities for a better integration of environmental issues in the choice of materials, and the value-added of such holistic tools regarding their decisionmaking process.

\subsection{Method}

In order to identify barriers to material efficiency, more specifically at the design phase (in particular material substitution, and light weighting), and to test the LCC tool as a change driver with decision-makers, we conducted a qualitative research [24] in the context of a French manufacturer.

Our work was based on two internal surveys, in the form of semi-directive interviews in person. The first internal survey was conducted with 8 techno-economic material experts and 4 managers in the Materials Engineering Department of the company (Tab. 4). The second internal survey was conducted with a subgroup of 5 techno-economic experts, covering the following materials: metallic materials (foundry, long products, and flat products), polymers, and electrical and electronic materials.

\subsubsection{1st internal survey: barriers to material efficiency} (from July to September 2018)

The survey aimed to identify the barriers to material change and innovation, but also the barriers to considering materials environmental impacts in decision making, from the managers and material experts' perspectives. The semiopen interviews were based on an interview guide consisting of 3 parts:

- a first part to clarify the interviewee's mission, scope of action, time horizon and objectives;
Table 4. Summary of interviews with experts and managers.

\begin{tabular}{lcc}
\hline Experts & $\begin{array}{l}\text { Number of } \\
\text { interviews } \\
\text { (experts) }\end{array}$ & $\begin{array}{l}\text { Number of } \\
\text { interviews } \\
\text { (managers) }\end{array}$ \\
\hline 1st survey & 8 & 4 \\
2nd survey & 5 & $/$ \\
\hline
\end{tabular}

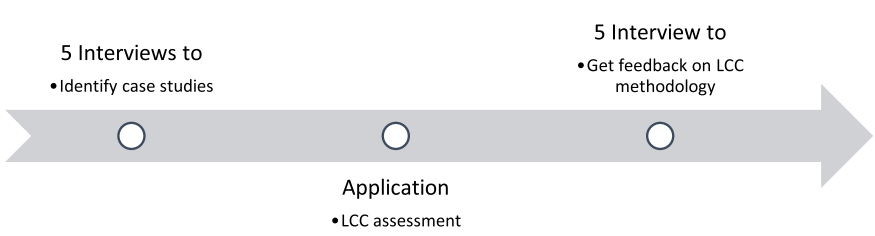

Fig. 11. Organization of the 2nd internal survey on the Life Cycle Costing tool.

- a second part to shed light on the determinants and obstacles to innovation in the field of materials and materials substitution;

- a third part to highlight the obstacles to taking environmental issues into account in decision-making.

\subsubsection{2nd internal survey: testing the LCC tool (from} November 2018 to January 2019)

In order to investigate the potential impact of the LCC tool on the company and the decision-makers' perspectives on materials' values, we conducted an internal qualitative study, the first step of which was to meet the material experts to get their opinions on the relevant case studies (parts of the vehicle) for our exploration. Then the second step consisted in applying our LCC methodology to each selected part, while the third step consisted in presenting the results to the experts and collecting their feedbacks individually, on our LCC methodology, on the potential value-added of this kind of tools and on its integration into their decision-making process. The organization of the study is illustrated by the Figure 11.

NB: only LCC results at the scale of parts (see Sect. 1.3.1) have been exposed to materials expert.

None of the interviews was transcribed nor $\operatorname{coded}^{4}$, because recording was not possible due to confidentiality issues. Indeed, the qualitative data collected consisted in notes taken during the interviews. Salient and recurrent elements were extracted from the answers of interviewees, based on their relevance regarding our research questions.

\subsection{Results}

\subsubsection{Survey 1: barriers to material efficiency and} environmental impacts consideration

\subsubsection{Barriers to material efficiency}

Our first internal survey allowed us to identify several interrelated factors influencing decisions regarding materi-

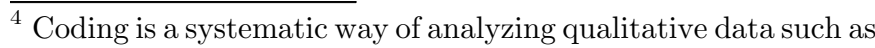
transcribed interviews by categorization and abstraction [25].
} 
al use from the material experts' and managers' perspectives, which can be summarized as follows: (1) technical constraint; (2) value chain structure; (3) customer value; (4) sourcing; (5) industrial strategy; (6) time shortening. These factors reveal some design, production and market requirements that make it difficult to change the use of materials.

\subsection{Technical constraints}

Material substitution is one of the material efficiency strategies at the design phase [16]. However, substitution is not always an option, as some highly specific functions can only be performed by a single type of material with unique properties. This is the case for instance of electronic applications, depollution, and electric cars' batteries. Moreover, when a certain substitutability is possible, it can generate additional costs that do not allow the compromise between technical and economic performance criteria to be reached.

"In my field, there are not always alternatives. It is the technical criterion that weighs the most". Expert on Materials for electrical and electronics

Indeed, in the field of electronics many materials have unique properties in terms of electronic structure and crystal structure, which makes them non-substitutable. Examples of that are rare earth elements in magnets, nickel and lithium in electric batteries, silicon and silicon carbide in semiconductors, etc.

\subsection{Value chain structure}

The current structure of the value chain of the French automotive sector, based on a partial outsourcing of R\&D and innovation costs to automotive suppliers (who base their business models on innovation and economies of scale). Indeed, some of the automobile parts are manufactured internally (in which case the raw material is purchased directly), and some are manufactured externally. In the latter case, the car manufacturer acts as a prescriber for automotive suppliers.

"The company is responsible for the fact that a part fulfils its role, the supplier is responsible for the choice of materials (specification), but sometimes there are material bans" Manager in the field of metallic materials

\subsection{Customer value}

What the end customer agrees to pay for a certain function (called customer value) has a significant impact on vehicle design choices. This depends on the profile of the consumers targeted, and therefore on the brand's positioning on the market. For example, customers' willingness to pay in the luxury vehicle market is not the same as that of mid-range brands, which do not offer the same flexibility in terms of increased production costs. In addition, some innovations, although representing considerable technical progress, may not be implemented in vehicles if they are invisible to the customer in terms of functionality, aesthetics or economic gain (see Sect. 1.2.2.3).

"People tell themselves: I will try, as much as possible, to avoid innovations that the customer does not see" Expert in the field of Metallic materials

\subsection{The sourcing strategy}

According to the interviewees, one of the most important constraints to be taken into account in design choices is the local sourcing strategy, which requires the availability of materials in the relevant geographical areas.

"We buy locally near the foundries to reduce customs and logistics costs" Expert in Metallic Materials

Moreover, the sourcing strategy also involves standardization, in order to reduce costs through reduced purchasing costs, and improved supplier delivery performance among others [26]. It is also necessary to ensure that sufficient quantities of the materials in question are available:

"There are huge volume effects. We have to ensure availability. We rely on material suppliers, who incur heavy investments" Manager in the field of metallic materials

\subsection{The industrial strategy}

Another barrier to change in material use is the industrialization requirements. For example, material substitution may induce an industrial problem due to a machining problem, a heat treatment, or because of manufacturing equipment availability. This expert insists on the heavy industrial investments induced, for example, by the substitution of one foundry material by another:

"A foundry is dedicated to a material, it is a very, very important work, even if the change in question consists in moving from one grade of cast iron to another." Expert in Metallic Materials

\subsection{Time costs of change}

The implementation of a new solution in terms of material use induces an additional workload throughout the company. The availability of people to take on this extra work is also a constraint to consider. Indeed, each "new" material (in a given function) must undergo a characterization process. The costs of characterizing materials 
reinforce the inertia and standardization that characterize the use of certain materials. This task, perceived as timeconsuming, contributes to the opposition to the change of materials by the actors:

"I cannot spend my time making characterizations, knowing that we need a certain standardization of products" Expert in the field of Metallic Materials

This effect is exacerbated by the shortening of innovation cycles in the automotive industry, and therefore of production schedules and deadlines:

"We produce vehicles in 3 years instead of 5, we require suppliers to meet tighter deadlines, we want to use materials we already know to simplify validations" Polymer Expert

\subsubsection{Barriers to environmental impact considerations in material choice}

Another objective of this work was to identify some obstacles to taking materials environmental impacts into account in decision making in the automotive industry in general, and in the choice of materials in particular. Our discussions revealed factors related to the organization and KPIs of the company, but also to environmental impact assessment tools, and a certain vision of environmental issues. Indeed, in large structures such as multinationals, divisional organization involves a certain segmentation of activities, monitored and controlled separately, resulting in individual performance indicators. However, improving the environmental performance of products requires a collective effort and cross-cutting action, whose additional costs cannot be allocated to a single link in the chain.

"If we want to play collectively, we must be rewarded collectively. However, the performance indicators are all individual" Expert in the field of Metallic materials

"Why is it up to me to take responsibility for the choices of others, what's in it for me?" Polymer Expert

Moreover, it is very hard to value an environmental improvement, if there is no regulatory penalty or subsidy, nor a potential increase in customer value at stake. Indeed, the widespread idea on this issue in the company (which is based on historical empirical observations) is that customers don't value eco-friendly efforts from car manufacturers, and even less when it comes to mandatory efforts (for example for the compliance with regulations on pollutant emissions).

"The average customer doesn't care, what interests him/ her is his/her health and wallet" Expert in metallic materials

Some research in marketing seems to corroborate this assumption [27], but it is without taking into account the expectations of the new generations [28].
Furthermore, the association of environmental impacts with direct penalties is exacerbated by the short-term profitability objectives imposed to all kinds of investments in the company, which prevents from considering long term stakes in decision-making.

"KPIs are based on short-term profitability, but the most profitable in the short term is rarely the best solution" Polymer Expert

"Sometimes solutions are eliminated because they do not contribute to the operating margin" Polymer Expert

Besides, it seems that there is in an issue of compatibility between the scope and degree of finesse of impact assessment tools such LCA, and the operational needs of material's expert. Indeed, LCAs can be conducted in the perimeter of a country, a region (by considering the energy mix of the countries for example) or a global scale, which often requires the use of secondary databases to complete primary data. Indeed, these large perimeters make it very difficult to adapt processes to better account for regional technological specificities (inventory regionalization) [29], which reduces the representativeness of LCA results at small scale. Knowing that material experts' decisions are very local (it consists for example of choosing between two suppliers), this leads to a certain incompatibility between the tool and the users' needs, i.e material experts needs in this case.

"In life cycle analysis, today's models are far too general, but details are important" Expert in Metallic Materials

\subsubsection{Survey 2: decision makers' feedbacks on the LCC tool}

Our discussions with the five material experts shed light on several methodological improvement avenues and allowed to reveal the potential applications of these kind of approaches from the interviewees' perspectives. One of the main axes of discussion was the validity of the approach and results regarding design and production requirements. For example, a question arose about the relevance of an analysis at the scale of a vehicle part, rather than a technological system or module, or an industrial system. Indeed, one of the limitations of the analysis at the scale of a part is related to potential connection issues that can be missed with this limited scope, as this may change the conclusion about the LCC of particular parts (for example electrical cables).

"A cable is not alone, a cable is a sheath and a connector, you can't separate the two" Electric materials Expert

This approach also masks the threshold and volume effects, as well as the stakes of raw material availability and industrialization, which is a characteristic of productoriented methods. The substitutability of materials in parts is also a strong assumption, as change in materials may also change the design of the part: 
"Switching from cast iron to steel allows smaller dimensions, it reduces friction by $30 \%$. Not everything is substitutable as it is claimed, the problem is more complex than that, it depends on too many parameters" Expert in the field of metallic material

These discussions refer to a classical debate in the design and eco-design communities, in particular about cut-off criteria and functional units used in LCA [30-33]. For example, the issues of functional units are addressed from a methodological point of view, by encouraging the use of functional units that are as much as possible related to the functions of the products rather than to the physical products, to ensure that all the required properties are addressed. Concerning cut-off criteria, which define which processes are included in the system analyzed and the permissible uncertainty, it depends on the LCA methodology (attributional or consequential) but also the goal of the study in question. According to axiomatic design theory [34], the modularity of the system also determines the relevant perimeter. Indeed, the more the design is coupled (with several parts that are interdependent), the more it is necessary to widen the perimeter around the elementary component which is on focus of the analysis.

However, there is little discussion about the relevance of these different methodological choices from a company's perspective as a basis for a strategy to reduce environmental impacts [35]. Indeed, in order to ensure that these kind of assessment tools are taken in hand by relevant actors in the company and have an impact on decision-making processes, they must respect scientific standards to ensure their credibility - especially in an engineering companybut also company-specific codes and procedures [36], for example by ensuring that the scale of analysis corresponds to a certain targeted stage in the design process, to certain missions and certain actors. Indeed, our experience has shown that otherwise, it is very unlikely that people will feel involved in this process of change and this would result in very little impact on the decision-making process.

Moreover, experts considered that assimilating the costs for the company to raw materials costs based on market prices is not realistic in some cases and introduces a strong bias in the results. Besides, price volatility of some indexed commodities is also not captured by the methodology, which constitutes a limitation. They also expressed the need of more local conclusions, as the results presented were calculated in a European perimeter, with average European values for the electricity mix for example.

"What is the impact of the choice of supplier? The geographical dimension is to be added" Flat products Expert

In addition to the methodological discussions with the interviewees, we also discussed the usefulness of these results in their respective areas. It seems that according to the interviewees, valuing environmental impacts in monetary terms could serve as a basis for discussion and negotiation with regulation authorities, or as an additional (but not decisive) argument to build the case for some materials (for example aluminum which is sometimes in competition with steel).

This reflects a top-down vision of initiatives for improving environmental impact in the company. In fact, our discussions with the interviewees revealed that for them, improving the situation in terms of sustainability is not really part of the mission or capacities of experts or managers, but is rather between the hands of top management and/or regulatory authorities. This reveals the need for additional research to explore the drivers within companies towards sustainability transitions and the potential of management tools as a means of stimulating efforts towards this type of initiative in a bottom-up way [37].

"You have to try to turn your tool into something that will be used by the government so that it becomes a criterion" Expert in Metallic Materials

\subsection{Discussion}

Our internal qualitative surveys made it possible to better understand the complexity and multidimensionality of materials use and management, the barriers to material efficiency in the French automotive industry, and the integration of materials environmental impacts as a decision criterion. Indeed, our position has allowed us to observe an automobile manufacturer from the inside, in the context of an intervention-research [38], which helped us reveal very practical decision determinants.

Our findings illustrate the dependency of material use with other issues such as customer value proposition of the company, sourcing constraints, industrial requirements or organizational attributes. The interviews also highlighted some lock-in mechanisms regarding the internalization of environmental externalities in decision-making, in particular through a management tool such as LCC.

Indeed, in addition to investigating the factors that favor inertia in material use in the company, we inquired about the potential of a management tool that highlights the environmental externalities in monetary terms to act as a driver of change towards a more sustainable use of materials. This led to interesting methodological discussions with material experts, which made it possible to compare theoretical and operational visions and highlighted the need for this exchange between designers and users of management tools, in order to reach a compromise between the representativeness and feasibility of the assessment. These discussions also shed light on other determinants of decisions related to the use of materials and opened the way to a new research perspective. In fact, it would be interesting to explore how the material efficiency can be used as a design and business model criterion, rather than as a parameter to be retrospectively optimized.

Nevertheless, it should be kept in mind that these results are based on the perspective of a single company, and a limited set of individuals. Indeed, the results are marked by the company's culture and routines that result 
among others from its history. This was manifest in particular in the predominance of a short-term culture and a certain vision of environmental issues and performance. All things considered, the organizational model based on segmented and often short-term and segmented performance indicators is the dominant model in large multinational companies, which makes it possible to generalize some of the conclusions without too much risk.

\subsection{Concluding comments}

This study illustrates some of the socio-technical issues related to materials in the automotive sector, but also confirms the relevance of this type of approach through a dialogue with experts in the field. Therefore, we believe that this constitutes an interesting avenue of research that will become more important with the increasing scarcity of resources, the evolution of vehicle material content due to innovation trends (electrification, digitalization and autonomation) and to stricter European regulations.

An example of a research approach would be to focus on the issues specific to each category of materials. Indeed, the market structure and production processes are not the same for metals or polymers. It would also be relevant to look at other material efficiency strategies at the level of manufacturing and use phases, by going beyond the framework of materials (new business models, circularity, increasing the value of end-of-life materials, etc.).

\section{References}

1. J.-C. Moisdon, A. Hatchuel, Du mode d'existence des outils de gestion, Actes du séminaire Contradictions et Dynamique des Organisations-CONDOR-IX, 6, 1997

2. E. Chiapello, P. Gilbert, Sociologie des outils de gestion, 3, Éditions La Découverte, Paris, France, 2014

3. European Commission, Regulation (EC) No. 443/ 2009 of the European Parliament and of the Council, Official Journal of the European Union, Luxembourg, Luxembourg, 2009

4. R.B. Howarth, Status effects and environmental externalities, Ecol. Econ. 16(1), 25 (1996), https://doi.org/10.1016/ 0921-8009(95)00076-3

5. ScoreLCA, Life Cycle Costing: description méthodologique et mise en oeuvre ( $\mathrm{n}^{\circ}$ Étude $\left.\mathrm{n}^{\circ} 2016-03\right)$, Score LCA, Villeurbanne, France, 2018

6. A. Anya Phelan, L. Dawes, R. Costanza, I. Kubiszewski, Evaluation of social externalities in regional communities affected by coal seam gas projects: A case study from Southeast Queensland, Ecol. Econ. 131, 300 (2017), https://doi.org/10.1016/j.ecolecon.2016.09.010

7. B. Steen, Calculation of monetary values of environmental impacts from emissions and resource use, The case of using the EPS 2015d Impact Assessment Method, J. Sustain. Dev. 9(6), 15 (2016), https://doi.org/10.5539/jsd.v9n6p15

8. L. d'Andrea, A. Declich, F. Feudo, Hidden societal implications of materials, Updating the awareness on what is at stake, Matériaux \& Techniques 102(5), 504 (2014), https://doi.org/10.1051/mattech/2014020

9. J.S. Thomas, A. Carvallo, J.P. Birat, Metrics for the sustainability value of steel, Matériaux \& Techniques 102 (5), 505 (2014), https://doi.org/10.1051/mattech/2014029
10. M.B. Holbrook, Consumer Value: A framework for analysis and research, Routledge, United Kingdom, 1999

11. C. Koffler, K. Rohde-Brandenburger, On the calculation of fuel savings through lightweight design in automotive life cycle assessments, Int. J. Life Cycle Assess. 15(1), 128 (2010), https://doi.org/10.1007/s11367-009-0127-z

12. Volvo, KPMG, True Value case study, Volvo Group, KPMG, Amsterdam, Netherlands, 2015, accessed at https://assets. kpmg/content/dam/kpmg/pdf/2015/10/volvo-group-kpmgtrue-value-case-study.pdf

13. Solvay, Sustainable Porfolio Management guide: Driving long-term sustainable growth, Solvay, Brussels, Belgium, 2017

14. International Energy Agency, Energy technology perspectives, in: Deploying renewables: Principles for effective policies, International Energy Agency, OECD, Paris, 2008, pp. 15-198, https://doi.org/10.1787/9789264042216-1-en

15. J.M. Allwood, J.M. Cullen, Sustainable materials: With both eyes open, UIT Cambridge, Cambridge, United Kingdom, 2012

16. J.M. Allwood, M.F. Ashby, T.G. Gutowski, E. Worrell, Material efficiency: A white paper, Resour. Conserv. Recycl. 55(3), $362 \quad$ (2011), https://doi.org/10.1016/j.rescon rec.2010.11.002

17. M.F. Ashby, Materials and the Environment, 2nd Edition, Elsevier, 2012, accessed at https://www.elsevier.com/ books/materials-and-the-environment/ashby/978-0-12385971-6

18. P. Lindahl, K.-H. Robèrt, H. Ny, G. Broman, Strategic sustainability considerations in materials management, J. Clean. Prod. 64, 98 (2014), https://doi.org/10.1016/j. jclepro.2013.07.015

19. E. Zervas, Analysis of the $\mathrm{CO}_{2}$ emissions and of the other characteristics of the European market of new passenger cars, 1. Analysis of general data and analysis per country, Energy Policy 38(10), 5413 (2010), https://doi.org/10.1016/j. enpol.2010.02.008

20. ICCT, European vehicle market statistics 2018/2019, 64, International Council on Clean Transport, Washington, USA, 2019

21. S. Cooper, B.J. Doody, J.M. Allwood, Socio-technical factors influencing current trends in material throughput in the UK automotive industry, J. Clean. Prod. 156, 817 (2017), https://doi.org/10.1016/j.jclepro.2017.04.014

22. F.W. Geels, A socio-technical analysis of low-carbon transitions: Introducing the multi-level perspective into transport studies, J. Transp. Geogr. 24, 471 (2012), https://doi.org/10.1016/j.jtrangeo.2012.01.021

23. A. David, Outils de gestion et dynamique du changement, «Les organisations face au changement », Rev. Fr. Gest. 120, 44 (1998)

24. H. Dumez, Comprehensive research: A methodological and epistemological introduction to qualitative research, Copenhagen Business School Press, Frederiksberg, Danemark, 2016

25. M. Ayache, H. Dumez, Le codage dans la recherche qualitative une nouvelle perspective? Le Libellio d'AEGIS 7(2-Été), 33 (2011)

26. C. Sánchez-Rodríguez, D. Hemsworth, Á.R. MartínezLorente, J.G. Clavel, An empirical study on the impact of standardization of materials and purchasing procedures on purchasing and business performance, Supply Chain Manag. Int. J. 11(1), 56 (2006), https://doi.org/10.1108/ 13598540610642475 
27. A. Russo, D. Morrone, D. Calace, The green side of the automotive industry: A consumer-based analysis, J. Market. Dev. Compet. 9(2), 59 (2015)

28. D.-C. Dabija, B.M. Bejan, V. Dinu, How sustainability oriented is generation $\mathrm{Z}$ in retail? A Literature Review, Transform. Bus. Econ. 18(2), 140 (2019)

29. L. Patouillard, P. Collet, P. Lesage, P. Tirado Seco, C. Bulle, M. Margni, Prioritizing regionalization efforts in life cycle assessment through global sensitivity analysis: A sector meta-analysis based on ecoinvent v3, Int. J. Life Cycle Assess. 24, 2238 (2019), https://doi.org/10.1007/s11367019-01635-5

30. European Commission, Joint Research Centre, ILCD handbook: General guide for life cycle assessment: detailed guidance, European Commission Joint Research Center, Brussels, Belgium, 2010, Accessed at http://lct.jrc.ec.europa. eu/pdf-directory/ILCD-Handbook-General-guide-for-LCADETAIL-online-12March2010.pdf

31. C. Gobin, Réussir une construction en éco-conception, Presses des Mines, Paris, France, 2010, accessed on 11th July 2019 at https://www.pressesdesmines.com/ website: https://www.pressesdesmines.com/produit/reussir-uneconstruction-en-eco-conception/
32. C. Industriteknik, C. Teknikpark, Choice of system boundaries in life cycle assessment, J. Clean. Prod. 2(1), 21 (1994)

33. B.P. Weidema, Short procedural guideline to identify the functional unit for a product environmental footprint and to delimit the scope of product categories, 2.-0 LCA consultants, Aalborg, Danemark, 2017, p. 20

34. N.P. Suh, Axiomatic design theory for systems, Res. Eng. Des. 10(4), 189 (1998), https://doi.org/10.1007/s001639870001

35. A.-M. Tillman, Significance of decision-making for LCA methodology, Environ. Impact Assess. Rev. 20(1), 113 (2000), https://doi.org/10.1016/S0195-9255(99)00035-9

36. H. Coutant, Les Synthèses de La Fabrique, «Qu'est-ce qu'une "boîte d'ingénieurs" ? », La Fabrique de l'industrie, Paris, France, 19, 2018

37. N. Iken, F. Aggeri, S. Morel, How to conduct a sustainability transition at the company level? The role of impact valuation tools and management instruments, R\&D Management Conference, Présenté à École Polytechnique, Palaiseau, France, 2019, accessed at https:// hal.archives-ouvertes.fr/hal-02170285

38. F. Aggeri, La recherche-intervention: Fondements et pratiques, in: J. Barthélémy, N. Mottis (Eds.), À la pointe du management. Ce que la recherche apporte au manager, Dunod, 2016, pp. 79-100

Cite this article as: Nabila Iken, Stéphane Morel, Franck Aggeri, Towards a sustainable material use in the automotive industry: Life Cycle Costing and socio-technical approach to material use, Matériaux \& Techniques 107, 504 (2019) 